Proc. of the X Int. Conf. — Ion Implantation and other Applications of Ions and Electrons, Kazimierz Dolny 2014

\title{
Fabrication and Characterization of Transparent Tin Dioxide Films with Variable Stoichiometric Composition
}

\author{
V.K. KSENEVICH ${ }^{a}$, D.V. AdAMChUK ${ }^{a}$, V.B. OdZhaEV ${ }^{a}$ AND P. ZUKOWSKI ${ }^{b, *}$ \\ ${ }^{a}$ Department of Physics, Belarusian State University, Nezalezhnastsi ave. 4, 220030 Minsk, Belarus \\ ${ }^{b}$ Lublin University of Technology, Nadbystrzycka 38d, 20-618 Lublin, Poland
}

\begin{abstract}
Tin dioxide films with variable stoichiometric composition were fabricated by means of dc magnetron sputtering followed by a 2-stage annealing process. The structural and electrical properties of tin dioxide films were investigated by means of the Raman spectroscopy and impedance spectroscopy, respectively. It was found that crystallinity and grain size of tin dioxide films increase with the increasing annealing temperature. The most conductive samples were obtained at the annealing temperature $375^{\circ} \mathrm{C}$. Increasing of the impedance of films annealed at higher temperatures is explained by decrease of the concentration of oxygen vacancies.
\end{abstract}

DOI: 10.12693 /APhysPolA.128.861

PACS: 73.61.Le, 78.30.-j, 81.15.Cd

\section{Introduction}

Coexistence of excellent optical transparency in the visible range of electromagnetic spectrum and high electrical conductivity of tin dioxide films provides possibility for variety of applications in optoelectronics [1]. It is well known that oxygen vacancies play a dominant role in the electrical properties of tin dioxide films [2]. Therefore possibility of tuning of stoichiometric composition of tin dioxide films during the fabrication process is a crucial task for a wide range of their applications. In spite of various techniques and methods used to prepare tin dioxide films fabrication of samples with desired physical and chemical properties still remains a challenge. Here we report a fabrication method of tin dioxide films with variable values of electrical conductivity. For the characterization of structural and electrical properties of tin dioxide films, the Raman spectroscopy and the complex impedance measurements technique were utilized.

\section{Experimental methods}

In order to fabricate $\mathrm{SnO}_{2-\delta}$ films with variable stoichiometric composition dc magnetron sputtering of tin target in Ar atmosphere with the following 2-stage annealing procedure in air was used. The 1st stage includes heating up to $200{ }^{\circ} \mathrm{C}$ and isothermal annealing for $2 \mathrm{~h}$, the 2nd stage - heating and subsequent isothermal annealing at different temperatures in the temperature interval $350-500^{\circ} \mathrm{C}$ for $1 \mathrm{~h}$. The Raman spectra were recorded using the 3D confocal Raman spectral-analytical system Nanofinder HE with a laser source at $\lambda=532 \mathrm{~nm}$. Measurements of the frequency dependences of the impedance

\footnotetext{
* corresponding author; e-mail pawel@elektron.pol.lublin.pl
}

$Z=Z^{\prime}+\mathrm{i} Z^{\prime \prime}$ of tin dioxide films in the frequency interval $20 \mathrm{~Hz}-2 \mathrm{MHz}$ were used for electrical characterization of the samples annealed at different temperatures. The LCR meter Agilent E4980A was used for the measurements of frequency dependences of real $Z^{\prime}$ and imaginary $Z^{\prime \prime}$ components of the impedance of tin dioxide films. The amplitude of the sinusoidal signal was $40 \mathrm{mV}$.

\section{Experimental results and discussion}

In order to vary electrical conductivity of tin dioxide films different annealing procedures were used. It was found that the 2-stage heat treatment process with the isothermal annealing at $20{ }^{\circ} \mathrm{C}$ (near the melting temperature of $\mathrm{Sn}$ ) followed by high temperature annealing in the temperature interval $375-450{ }^{\circ} \mathrm{C}$ provides possibility to fabricate conductive and transparent tin dioxide films. The Raman spectra for the samples annealed in the second stage at $375^{\circ} \mathrm{C}$ and $450^{\circ} \mathrm{C}$ are shown in Fig. 1. It is well known that the frequencies of vibration modes of $\mathrm{SnO}_{2}$ depend on the crystal size, shape and aggregation [3]. In our spectra several peaks (for example, at $111 \mathrm{~cm}^{-1}$ and at $750 \mathrm{~cm}^{-1}$ ) in the vicinity of the classical vibration modes $B_{1 g}$ (theoretically predicted at $121 \mathrm{~cm}^{-1}[4]$ ) and $B_{2 g}$ (theoretically predicted at $760.8 \mathrm{~cm}^{-1}$ [5]) for a single $\mathrm{SnO}_{2}$ crystal were observed. Besides the peaks at $314 \mathrm{~cm}^{-1}$ and $690 \mathrm{~cm}^{-1}$ can be attributed to the vibration modes $E_{u}(3)$ of transverse optical phonons and $A_{2 u}$ of longitudinal optical phonons, respectively [6]. A peak at $211 \mathrm{~cm}^{-1}$ is present in the spectra of the film annealed in the second stage at $375^{\circ} \mathrm{C}$. This peak corresponds to the $\mathrm{Sn}-\mathrm{O}$ vibrations in a tin oxide phase [7] formed as a result of oxidation of Sn film in air. Due to complete oxidation of metallic film at higher annealing temperature $\left(450^{\circ} \mathrm{C}\right)$ and formation of tin dioxide phase, this peak corresponding to the $\mathrm{SnO}$ phase was not observed. Thus, according to the Raman spectra we can assume that polycrystalline tin dioxide films with different grain size and stoichiometric composition were fabricated as a result of annealing procedure. 


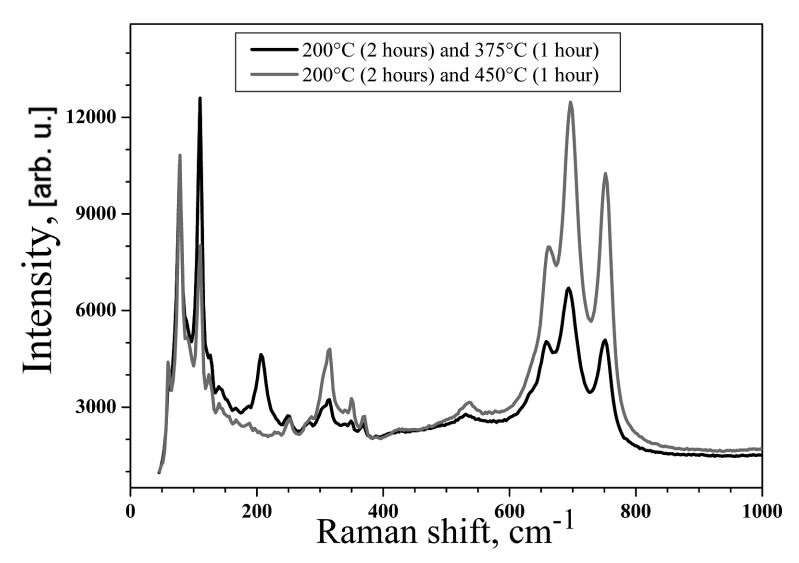

Fig. 1. Raman spectra of $\mathrm{SnO}_{2-\delta}$ films fabricated by dc magnetron sputtering of tin target followed by a 2stage heat treatment procedure.

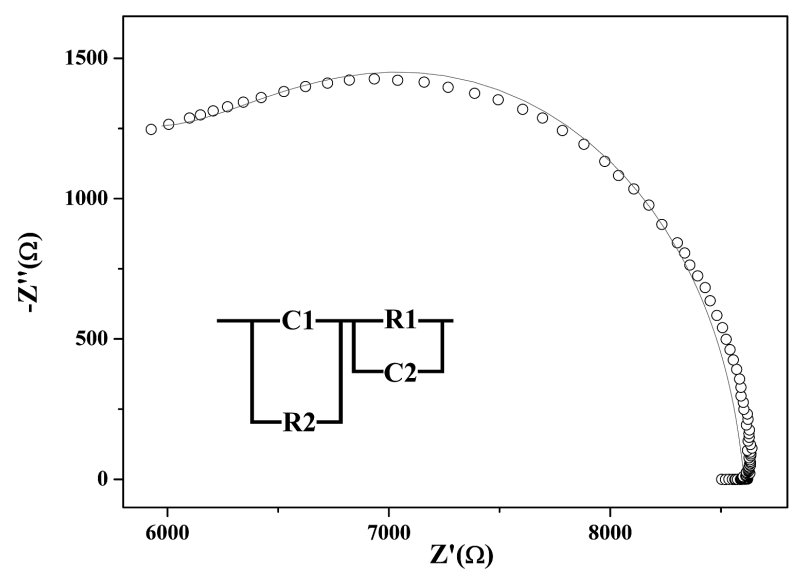

Fig. 2. Impedance diagram of $\mathrm{SnO}_{2-\delta}$ films fabricated by dc magnetron sputtering of tin target followed by heat treatment in air at $200{ }^{\circ} \mathrm{C}$ for $2 \mathrm{~h}$ and $375^{\circ} \mathrm{C}$ for $1 \mathrm{~h}$. The line is the approximation of the experimental data by an equivalent circuit shown in the inset.

This assumption was confirmed by the results of the complex impedance of tin dioxide films measurements. The impedance diagram of $\mathrm{SnO}_{2-\delta}$ films fabricated by dc magnetron sputtering of tin target followed by heat treatment in air at $200^{\circ} \mathrm{C}$ for $2 \mathrm{~h}$ and $375^{\circ} \mathrm{C}$ for $1 \mathrm{~h}$ is shown in Fig. 2. The points correspond to the experimental data while the solid lines represent the results of the calculations by means of the complex nonlinear leastsquare method (CNLS) [8]. The best fitting results were obtained by simulation of the experimental data with an equivalent scheme shown in the inset to Fig. 2. According to this scheme resistors $R 1, R 2$ and capacitances $C 1, C 2$ simulate resistance and capacitance of the grains volume and grains boundaries, respectively.

The impedance diagram of tin dioxide films annealed in the 2 nd stage of heat treatment procedure at $450{ }^{\circ} \mathrm{C}$ is shown in Fig. 3. It was found that real part of impedance of the samples increased in comparison with $Z^{\prime}$ value of $\mathrm{SnO}_{2-\delta}$ films annealed at $375^{\circ} \mathrm{C}$ in the 2 nd stage of heat

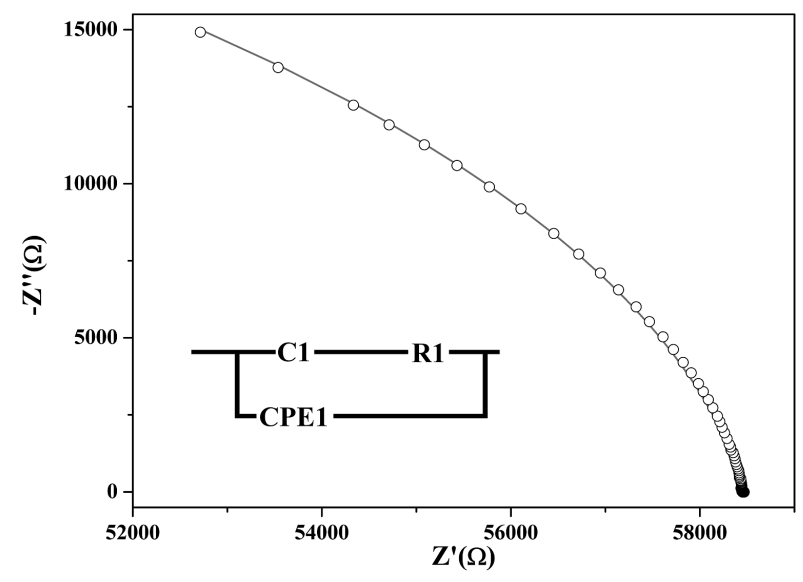

Fig. 3. Impedance diagram of $\mathrm{SnO}_{2-\delta}$ films fabricated by dc magnetron sputtering of tin target followed by heat treatment in air at $200^{\circ} \mathrm{C}$ for $2 \mathrm{~h}$ and $450{ }^{\circ} \mathrm{C}$ for $1 \mathrm{~h}$. The line is as in Fig. 2.

treatment procedure. This can be explained by decrease of oxygen vacancies concentration which provides $n$-type conductivity of tin dioxide films [9]. On the other hand, rise of the annealing temperature induces the increase of grains size and reduces potential barriers between them. As a result, the equivalent scheme for these samples shown in the inset to Fig. 3 was modified in comparison with that of tin dioxide films annealed at $375^{\circ} \mathrm{C}$ in the 2 nd stage of heat treatment procedure. Resistors $R 1$ and capacitances $C 1$ in this scheme simulate resistance and capacitance of the grain volume. The constant phase element (CPE) used in the equivalent scheme takes into account distribution in values of the resistance and capacitance of the grain boundaries. The admittance of the CPE is defined as [8]:

$$
Y_{\mathrm{CPE}}=A_{0}(\mathrm{i} \omega)^{\alpha}=A_{0} \omega^{\alpha}(\cos (\pi / 2 \alpha)+\mathrm{i} \sin (\pi / 2 \alpha)),
$$
where $A_{0}$ is the coefficient with the dimensionality depending on the $\alpha$ value. In the case $\alpha=1$, the value $A_{0}$ has the dimensionality of capacitance while in the case $\alpha=0$, the value $A_{0}$ has the dimensionality of resistance. In the intermediate case dimensionality of $A_{0}$ can be considered as $\Omega^{-1} \mathrm{~s}^{\alpha}$ [10]. As a result of modelling, it was found that $\alpha=0.94$, this means that CPE1 element corresponds to capacitance.

In order to enhance conductivity of the tin dioxide films annealed in the 2 nd stage of heat treatment procedure at $450^{\circ} \mathrm{C}$ these samples were subjected to the additional annealing in vacuum $\left(10^{-4} \mathrm{mbar}\right)$ at $450^{\circ} \mathrm{C}$ for $1 \mathrm{~h}$. Typical impedance diagram for these samples is presented in Fig. 4. The best fitting results were obtained by simulation of the experimental data with the same equivalent scheme as for the samples fabricated without vacuum annealing. However, it was found that the parameter $\alpha$ is close to $0\left(\alpha \approx 10^{-3}\right)$ assuming that CPE1 element corresponds to resistance. Essential variation of parameter $\alpha$ can be explained by the increase of grains size, decrease of potential barriers between them, redistribution of oxygen vacancies, and rising of their concentration. 


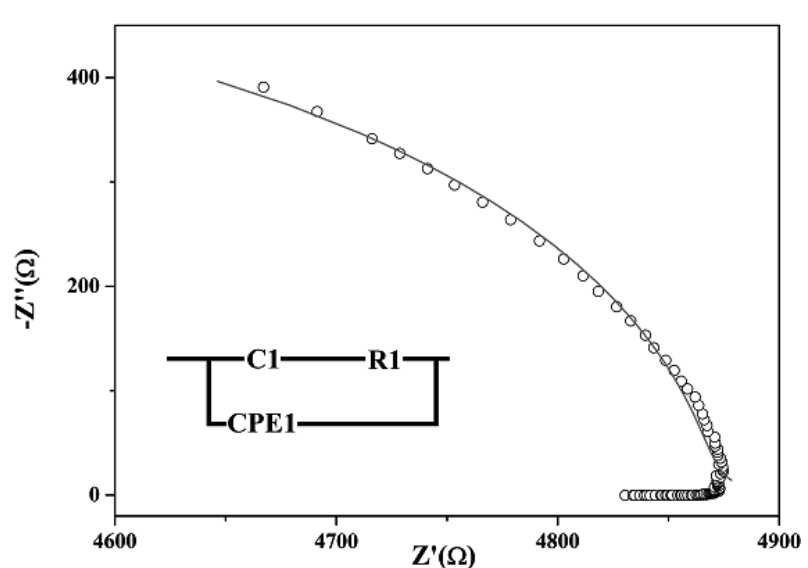

Fig. 4. Impedance diagram of $\mathrm{SnO}_{2-\delta}$ films fabricated by dc magnetron sputtering of tin target followed by heat treatment in air at $200^{\circ} \mathrm{C}$ for $2 \mathrm{~h}$, at $450{ }^{\circ} \mathrm{C}$ for $1 \mathrm{~h}$ and in vacuum at $450^{\circ} \mathrm{C}$ for $1 \mathrm{~h}$. The line is as in Fig. 2 .

\section{Conclusions}

Fabrication procedure for preparation of $\mathrm{SnO}_{2-\delta}$ films with different stoichiometric composition was developed. Tin dioxide films were synthesized by means of dc magnetron sputtering followed by a 2 -stage annealing procedure. As a result of the analysis of the Raman spectra and impedance diagrams of the samples it was found that the polycrystalline tin dioxide films with different sizes of grains were obtained. Electrical properties of tin dioxide films were found to depend on the oxygen vacancies concentration as well as on the grain volume and grain boundary contribution to conductivity. The additional annealing in vacuum was found to enhance tin dioxide films conductivity as a result of increase of grains size, decrease of potential barriers between them and rise of oxygen vacancies concentration.

\section{Acknowledgments}

The work was supported by the National Research Program "Convergence" (grant no. 3.1.04.1).

\section{References}

[1] S. Mathur, S. Barth, H. Shen, J.C. Pyun, U. Werner, Small 1, 713 (2005).

[2] M. Batzill, U. Diebold, Prog. Surf. Sci. 79, 47 (2005).

[3] A. Dieguez, A. Romano-Rodriguez, A. Vila, J.R. Morante, J. Appl. Phys. 90, 1550 (2001).

[4] M.E. Striefler, G.R. Borschi, Phys. Status Solidi B 67, 143 (1975).

[5] T. Sato, T. Asari, J. Phys. Soc. Jpn. 64, 1193 (1995).

[6] L. Abello, B. Bochu, A. Gaskov, S. Koudryavtseva, G. Lucazeau, M. Roumyantesva, J. Solid State Chem. 135, 78 (1998).

[7] E.L. Peltzer y Blanka, A. Svane, N.E. Christensen, C.O. Rodriguez, O.M. Cappannini, M.S. Moreno, Phys. Rev. B 48, 15712 (1993).

[8] I.D. Raistrick, D.R. Franceschetti, J.R. Macdonald, in: Impedance Spectroscopy: Theory, Experiment, and Applications, Eds. E. Barsoukov, J.R. Macdonald, Wiley, Hoboken, NJ 2005, p. 27.

[9] K.G. Godinho, A. Walsh, G.W. Watson, J. Phys. Chem. C 113, 439 (2009).

[10] M. Sluyters-Rehbach, Pure Appl. Chem. 66, 1831 (1994). 